\title{
Egg-size and -number variations related to maternal size and age, and the relationship between egg size and larval characteristics in an annual marine gastropod, Haloa japonica (Opisthobranchia; Cephalaspidea)
}

\author{
Kenji Ito* \\ Department of Marine Biological Science, Faculty of Fisheries, Hokkaido University, Hakodate 041, Japan
}

\begin{abstract}
Contrary to the traditional egg size-number trade-off model, egg size of the small opisthobranch Haloa japonica varies significantly within a population. To examine the cause of this variation, l estimated (1) the effects of maternal size and age (i.e. the number of days after the onset of breeding the egg was spawned) on egg size and number, and (2) the relationship between egg size and several larval characterıstics, including larval size, length of survival under conditions of starvation, and time to hatching. Egg size and number decreased in the course of the breeding season under laboratory conditions and egg size increased with maternal size. Length of survival under conditions of starvation was positively correlated with egg volume. This reproductive pattern is similar to that of other taxonomic groups, such as annual plants, insects and a marine polychaete. The decrease of reproductive investment is best explained as a maternal investment strategy related to maternal mortality, as proposed by Begon \& Parker (1986; Oikos 47:293-302). My data support the prediction of their theory.
\end{abstract}

KEY WORDS: Egg-size variation - Egg-number variation - Maternal size and age Intrapopulation Life-history theory - Opisthobranch - Haloa japonica

\section{INTRODUCTION}

Many studies of gastropods have examined egg-size variation among populations (Thompson 1967, Hirano \& Hirano 1991), among individuals within a population (Eyster 1979, Tomiyama \& Miyashita 1992, Estebenet \& Cazzaniga 1993, Baur 1994, Gibson \& Chia 1995), and among clutches from an individual (Baur 1990, Estebenet \& Cazzaniga 1993)

In contrast to empirical evidence for egg-size variation within a population, the traditional offspring sizenumber trade-off model (Smith \& Fretwell 1974) predicts that organisms of the same species growing in the same environment should spawn eggs of a constant size. The model of Smith \& Fretwell explains egg-size

\footnotetext{
•E-mail: itoken@pop.fish.hokudai.ac.jp
}

variation among populations under different environmental conditions as the result of differences in optimal egg size among those populations. Egg-size (and larval type) variation within gastropod populations has been explained as polymorphism (Eyster 1979) or as an adaptation for seasonal environmental change (Baur 1990). However, this contradiction between the prediction of egg-size constancy and the observed variation in egg size within populations has not been fully explored.

Egg-size variation within gastropod populations might also be due to variation in maternal characteristics. Many authors have reported that egg size is related to maternal characteristics, such as body size and age, in various organisms from other classes (review by Roff 1992). For example, offspring size decreases with maternal age in many organisms, such as annual plants (Cavers \& Steel 1984, Thompson \& 
Pellmyr 1989, Stamp 1990, Kane \& Cavers 1992), insects (Wiklund \& Persson 1983, Ruohomäki et al. 1993, Braby \& Jones 1995), and a marine polychaete (Qian \& Chia 1992). Some authors have created models that consider the effect of maternal age on reproductive investment (Begon \& Parker 1986, Parker \& Begon 1986, McGinley 1989, Lalonde 1991). The effects of maternal age on egg size in gastropods, however, have not been fully investigated.

In this paper, I examine the effects of maternal size and age (i.e. the number of days after the first spawning the egg was spawned) on egg size and egg number in an annual opisthobranch, Haloa japonica (Pilsbry). Preliminary observation indicated that there is distinct egg-size variation among egg masses from the same population. To my knowledge, there have been no studies to determine whether egg-size variation includes the deviation due to maternal size and age in this species. In addition, I examined the effects of egg size on newborn offspring characteristics, such as length of survival under conditions of starvation, development time and larval size. Most reproductive investment theories (e.g. Smith \& Fretwell 1974، Begon \& Parker 1986) assume that larger eggs have a greater fitness than smaller ones. However, this relationship is not true for all organisms (Tessier et al. 1983, Wiklund \& Persson 1983, Tessier \& Consolatti 1989, Glazier 1992, Ruohomäki et al. 1993, Braby 1994, Bretagnolle et al. 1995).

\section{MATERIALS AND METHODS}

Study species. Haloa japonica is a small hermaphrodite opisthobranch of the family Haminoeidae and is widely distributed in Japan, ranging from Kyushu to Hokkaido, and along the coast of the Korean Peninsula (Hamatani 1986). H. japonica inhabits intertidal and subtidal substratum, and algal beds, and spawns sausage-shaped gelatinous egg masses containing yellow eggs (Fig. 1A, B) attached to substrate from spring to summer (Usuki 1966a, b, Ito et al. 1996). This species has a pattern of development typical of that of lecithotrophic opisthobranchs (Usuki 1966a).

Collection and maintenance. Haloa japonica adults were obtained from the intertidal rocky shore at Kattoshi, located along the southwest side of Hakodate Bay, southern Hokkaido, Japan ( $41^{\circ} 44^{\prime} \mathrm{N}, 140^{\circ} 36^{\prime} \mathrm{E}$ ). This population has 1 generation per year (Ito et al. 1996). Individuals in this population are usually found on red and green algae, such as Polysiphonia japonica Harvey and Monostroma angicava (Thuret) Wittrock (Ito et al. 1996). They also feed on some other green algae, such as Ulva sp. (Usuki 1966a, author's pers. obs.).

Haloa japonica adults were collected in mid-March before the beginning of the spawning season, and were maintained in an aquarium with filtered seawater at 14 to $16^{\circ} \mathrm{C}$, which falls within the range of ambient conditions. At the start of the experiment, each indi-
Fig. 1. Haloa japonica. Egg masses and eggs. (A) Normal egg mass, scale bar $=10 \mathrm{~mm}$ (B) normal eggs, scale bar $=500 \mu \mathrm{m}_{\mathrm{i}}(\mathrm{C}) \mathrm{ab}$ normal egg mass, scale bar $=10 \mathrm{~mm}_{\mathrm{i}}(\mathrm{D})$ abnormal egg string, scale bar $=500 \mu \mathrm{m}$
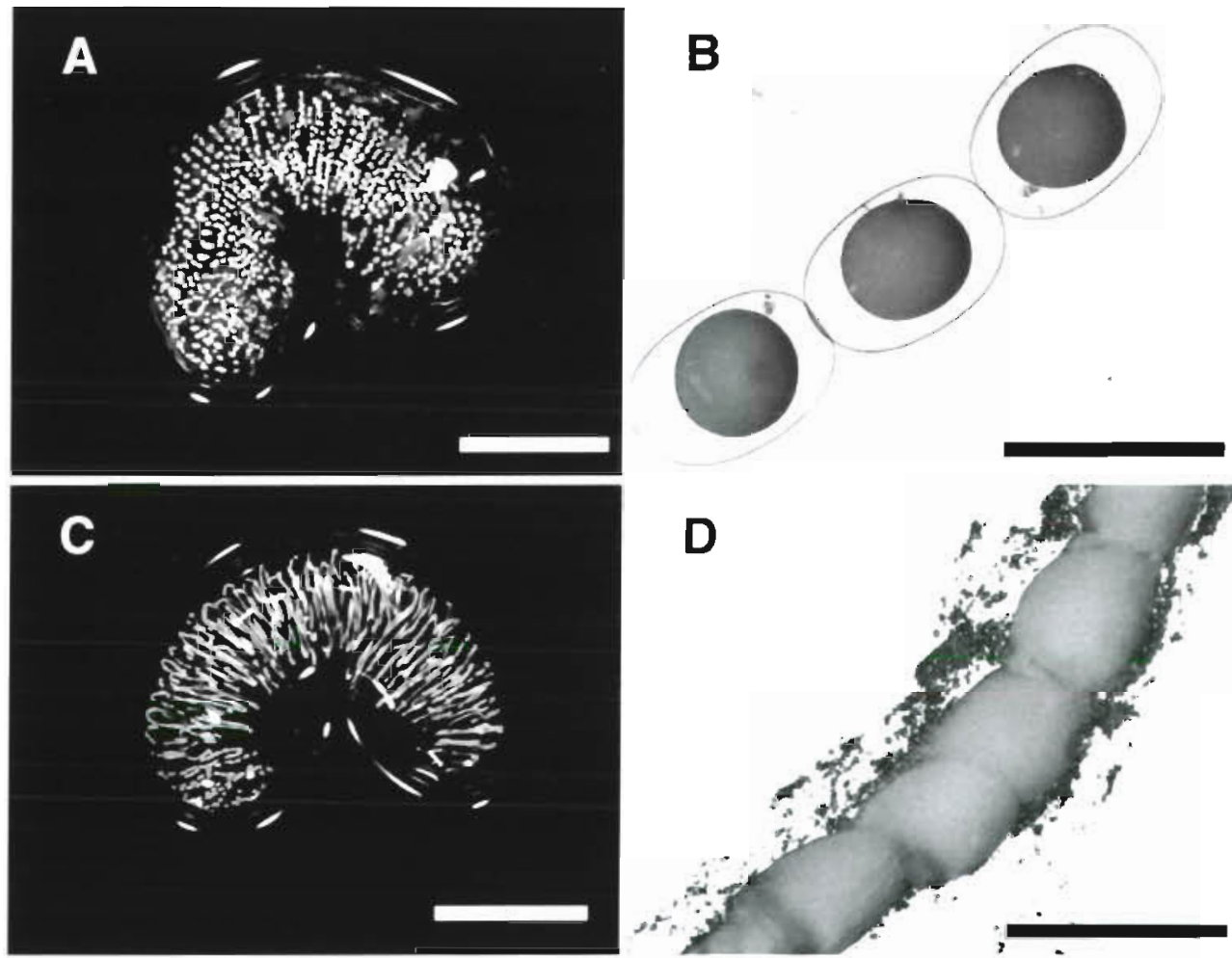
vidual was weighed to the nearest $0.1 \mathrm{mg}$ with an electronic balance and marked by the gluing of a plastic tag onto its shell. The gastropods were then placed into small individual cages made of polyethylene mesh $(\varnothing 50 \mathrm{~mm} \times 100 \mathrm{~mm})$ that allowed continuous water flow and were fed Monostroma angicava, Cheatmorphasp, and Ulva sp. ad libitum. Once a week, all individuals were placed in a single aquarium for $6 \mathrm{~h}$ to allow copulation. This weekly routine continued until all individuals died.

Adults of Haloa japonica that were provided sufficient food grew during the experimental period (Ito unpubl.) However, I weighed all individuals only at the start of the experiment in this study, because blotting $H$. japonica on paper towels to weigh them seemed to weaken them, especially aged individuals in the latter half of the experiment.

Efiects of maternal size and age on fecundity. I measured the reproductive traits of 19 individuals (wet weight range: 426 to $1796 \mathrm{mg}$ ) in the laboratory. Spawned egg masses were collected daily, and the egg size and number in each egg mass were measured.

The length and width of 10 uncleaved eggs, randomly chosen from each egg mass, were measured to the nearest $13 \mu \mathrm{m}$ using an ocular micrometer. Assuming an ellipsoid egg shape, egg volume was calculated from the formula,

$$
\text { Volume }=\frac{4}{3} \pi\left(\frac{l}{2}\right)\left(\frac{h}{2}\right)^{2}
$$

where $l$ and $h$ are the length and width of the eggs respectively. I did not measure eggs that had already begun developing.

In addition, I counted the egg number within each egg mass. Because some egg masses contained abnormal eggs that could not be distinguished from other eggs (Fig. 1C, D) I could not always count the number directly. Abnormal eggs did not develop. Thus, I expressed egg number in 2 ways: (1) actual egg number, which excluded abnormal eggs; and (2) potential egg number, which included all eggs. The latter was estimated as follows. First, each egg mass was weighed after excess fluid was removed. A portion of the egg mass (5 to $10 \mathrm{~mm}$ long) that contained normal eggs was cut from the mass and weighed to the nearest $0.1 \mathrm{mg}$ with a microbalance. The number of eggs within this fragment was counted under a binocular $(\times 70)$ and the egg concentration (egg number per mg egg mass) was calculated. The potential egg number was estimated by multiplying the weight of the egg mass by the egg concentration. If the egg mass contained only abnormal eggs, I used the mean egg concentration as a coefficient.

I used the Kruskal-Wallis test to compare mean egg volumes among spawning individuals. For this analy- sis, I pooled all egg-size data for each individual. I tested for the effects of maternal size and age on egg size and number using means of multiple regression analysis. Statistics for multiple regression models are given together with standardized partial regression coefficients and their p-values for statistically significant models. Confirmatory analysis using Wilcoxon's paired sample test between the first and last egg masses spawned was applied to the data. In addition, I analyzed the relationship between maternal wet weight and several characteristics of the first egg mass, such as the mean egg volume, egg number and weight of egg mass, by linear regression analysis to consider a prediction of the general life history theory proposed by Begon \& Parker (1986) (see 'Discussion'). All significance tests were set at the 0.05 level.

Egg size and offspring characteristics. I examined the egg-size effects on newborn offspring characteristics, such as development time, newborn larval size, and length of survival under conditions of starvation. During 3 to $7 \mathrm{~d}$ after hatching, most of the hatched, non-feeding veligers metamorphose into benthic larvae and begin to feed (Usuki 1966a, author's pers. obs.). The survival duration of these larvae under starvation conditions will be an effective indicator of the probability of access to a food resource and survival (see 'Discussion').

I gathered 17 egg masses immediately after they were spawned by 5 individuals. I collected 100 to 1000 eggs from each egg mass, removing the egg mass jelly to prevent slower development of inner embryos (Chaffee \& Strathmann 1984), and measured the volume of 10 eggs. Sample eggs were maintained in polystyrene tubes $(\varnothing 50 \times 80 \mathrm{~mm})$ at $16^{\circ} \mathrm{C}$. Culture water was replaced daily with $0.45 \mu \mathrm{m}$ filtered seawater. I recorded the number of days from spawning to first hatching. Newly hatched veligers were removed daily to disposable polystyrene dishes $(30 \times 30 \times 10 \mathrm{~mm})$, filled with $0.45 \mu \mathrm{m}$ filtered seawater. These culture dishes were rinsed before the experiment in distilled water. Each dish contained up to 20 individuals.

I measured the shell heights of 10 larvae from each dish. The veligers of Haloa japonica have a type I shell with an unflared aperture (Hurst 1967). To measure the shell height, I set each formalin-fixed veliger on a glass slide. Then, I turned the aperture side down, stabilized the shell orientation using tweezers, and measured the shell height with an ocular micrometer (Fig 2).

For individuals in the polystyrene dishes, I recorded the number of days from the first hatching date to death. Culture water was replaced daily with $0.45 \mu \mathrm{m}$ filtered seawater. Experiments continued until all individuals died so the mean time from hatching to death could be calculated for each egg mass. I used linear 


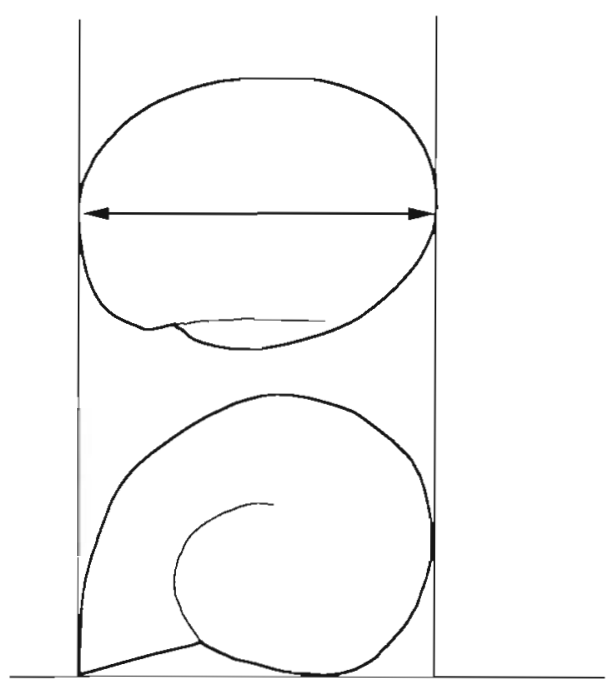

Fig. 2. Haloa japonica. Measurement of veliger shell height

regression analysis to estimate the relationship between egg size and length of survival, larval size, and developmental time. All significance tests were set the 0.05 level.
Table 1. Haloa japonica. Standard partial regression coefficlents of linear multiple regression on reproductive traits to maternal characteristics under laboratory conditions. $\left(\mathrm{r}^{2}:\right.$ coefficient of multiple determination ${ }^{n s}$ not significant at $5 \%$ level 'significant at $5 \%$ level; " significant at $1 \%$ level)

\begin{tabular}{|c|c|c|c|}
\hline \multirow[t]{2}{*}{ Reproductive traits } & \multicolumn{2}{|c|}{ Maternal characteristics } & \multirow[t]{2}{*}{$r^{2}$} \\
\hline & Weight & Age & \\
\hline Egg size & $0.309^{*}$ & $-0.601^{\cdots}$ & $0.454 \cdots$ \\
\hline No. of potential eggs & $0.111^{\mathrm{ns}}$ & $-0.273^{\bullet}$ & $0.062^{\circ}$ \\
\hline No. of actual eggs & $-0.170^{\mathrm{ns}}$ & $-0.354^{\circ}$ & $0.135^{\circ}$ \\
\hline
\end{tabular}

same individuals. The initial mean egg volume decreased significantly (Wilcoxon's signed rank test, $\mathrm{p}<$ 0.001 , Table 2 ) by an average of $17.6 \%$. The mean numbers of eggs from the first spawning were also significantly larger than from the last one (Wilcoxon's signed rank test, $p<0.05$, Table 2 ). Thus, there was an overall trend for egg size and number to decrease towards the end of the egg-laying period.

The relationships between maternal body size and the 3 first egg-mass traits (egg size, potential egg number, weight of egg mass) were all significant. However, the relationship between maternal size and first actual egg number was not significant (Fig. 4).

\section{Egg size and offspring characteristics}

\section{Egg-size and egg-number variation with maternal size and age}

I collected 80 egg masses from 19 individuals of Haloa japonica. I could only measure egg size in 68 of the 80 egg masses, because all the eggs in 12 egg masses had already developed. The number of egg masses laid by each individual varied from 1 to 9 (mean $\pm \mathrm{SE}_{;} 4.21 \pm 0.12, \mathrm{n}=19$ ). There was significant variation in mean egg size among individuals within the same population (Kruskal-Wallis test, $H=$ 146.349, $p<0.0001$ ).

The spawning experiment revealed a clear effect of maternal-size and ageeffects on egg size (Table 1). Mean egg size within egg masses decreased with maternal age, and increased with maternal wet weight (Table 1, Fig. 3). Both potential and actual egg number were also negatively related to maternal age. However, the relationship between maternal size and egg numbers was not significant (Table 1)

Table 2 shows the mean egg size of the first and last egg mass spawned by the
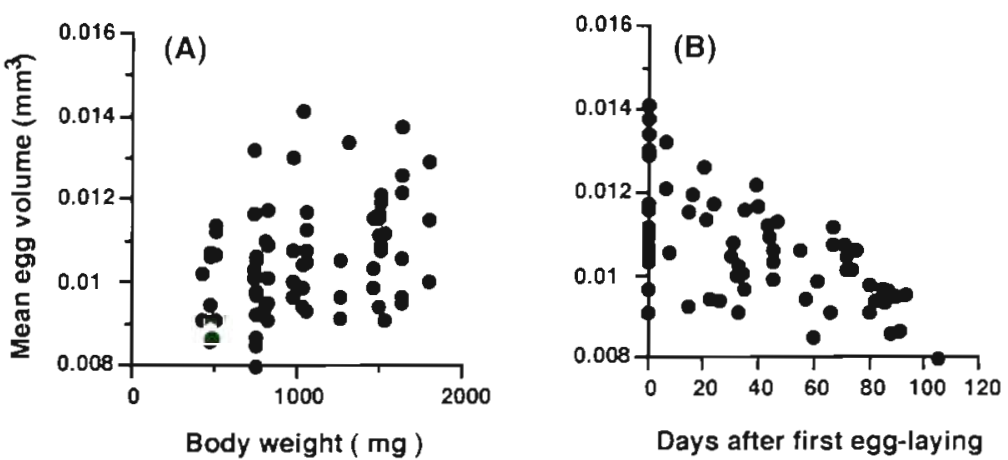

Fig. 3. Haloa japonica. Relations between (A) mean egg volume within egg mass and maternal size and (B) number of days after the onset of breeding the egg was spawned under laboratory conditions. Mean egg volume was calculated from 10 eggs in each egg mass. Each data point represents 1 egg mass. Statistics are represented in Table 1 
Table 2. Haloa japonica. Comparison of mean egg size and egg number between first and final (average time $\pm \mathrm{SE} ; 73.7 \pm 6.9 \mathrm{~d}$ ) egg mass spawned. Mean egg size calculated from 10 eggs. See 'Materials and methods' for definition of 'actual eggs' and 'potential eggs'

\begin{tabular}{|lcccc|}
\hline Reproductive traits & $\begin{array}{c}\text { Sample } \\
\text { size }\end{array}$ & $\begin{array}{c}\text { First egg mass } \\
( \pm \mathrm{SE})\end{array}$ & $\begin{array}{c}\text { Final egg mass } \\
( \pm \mathrm{SE})\end{array}$ & $\mathrm{p}$-value \\
\hline Egg volume $\left(\mathrm{mm}^{3}\right)$ & $\mathrm{n}=17$ & $0.0117 \pm 0.0003$ & $0.0095 \pm 0.0002$ & $\mathrm{p}<0.001$ \\
No. of actual eggs & $\mathrm{n}=17$ & $1066 \pm 136$ & $577 \pm 196$ & $\mathrm{p}<0.05$ \\
No. of potential eggs & $\mathrm{n}=17$ & $1454 \pm 136$ & $1004 \pm 177$ & $\mathrm{p}<0.05$ \\
\hline
\end{tabular}

size variation among egg masses was significant $\left(F_{16.138}=10.138, \mathrm{p}<0.0001\right.$, ANOVA $)$. Although larval development time and larval shell height were not correlated with egg size, survival time under starvation was positively correlated with egg volume (Fig. 5). These resuits indicate a positive correlation between egg size and offspring fitness in Haloa japonica, as general life- history theories have assumed (see 'Discussion'). is important to examine whether the pattern of egg-size decline is observed in other gastropod species.

In this paper, I assume that egg size is a reasonable indicator of reproductive investment. Most studies which have dealt with egg-size variation also used egg size as an index of maternal investment (e.g. Baur 1990). However, this assumption is not self evident. For example, the egg size of starfishes is not a reliable predictor of egg content in intraspecific life history studies (McEdward \& Carson 1987, McEdward \& Chia 1991). In the present study, there is no information on the relationship between egg size and organic material in this species. However, it may safely be assumed that egg size is one indicator of reproductive investment, along with nutrient content, yolk quantity etc., which affects larval fitness because larval survival duration was related to egg size (Fig. 5).

\section{DISCUSSION}

\section{Egg-size variation within the same population}

I showed that individual egg volume declines significantly with maternal age, and increases with maternal wet weight (Tables 1 \& 2). These results suggest that egg-size variation within a population of Haloa japonica is due to maternal size and age variations. Traditional life-history theories (e.g. Smith \& Fretwell 1974) predict that egg size should be constant under similar environmental conditions; for example, Yusa (1994) reported that there is no egg-size variation in the sea hare Aplysia kurodae related to maternal body size. However, many authors, such as Eyster (1979), have shown that gastropod egg size varies among individuals within a population. Maternal-age effects may explain this contradiction. Most studies of gastropods that deal with egg-size variation within populations have ignored the variation among clutches within individuals and the effects of maternal age on egg size. For precise comparisons of mean egg size, I believe that it
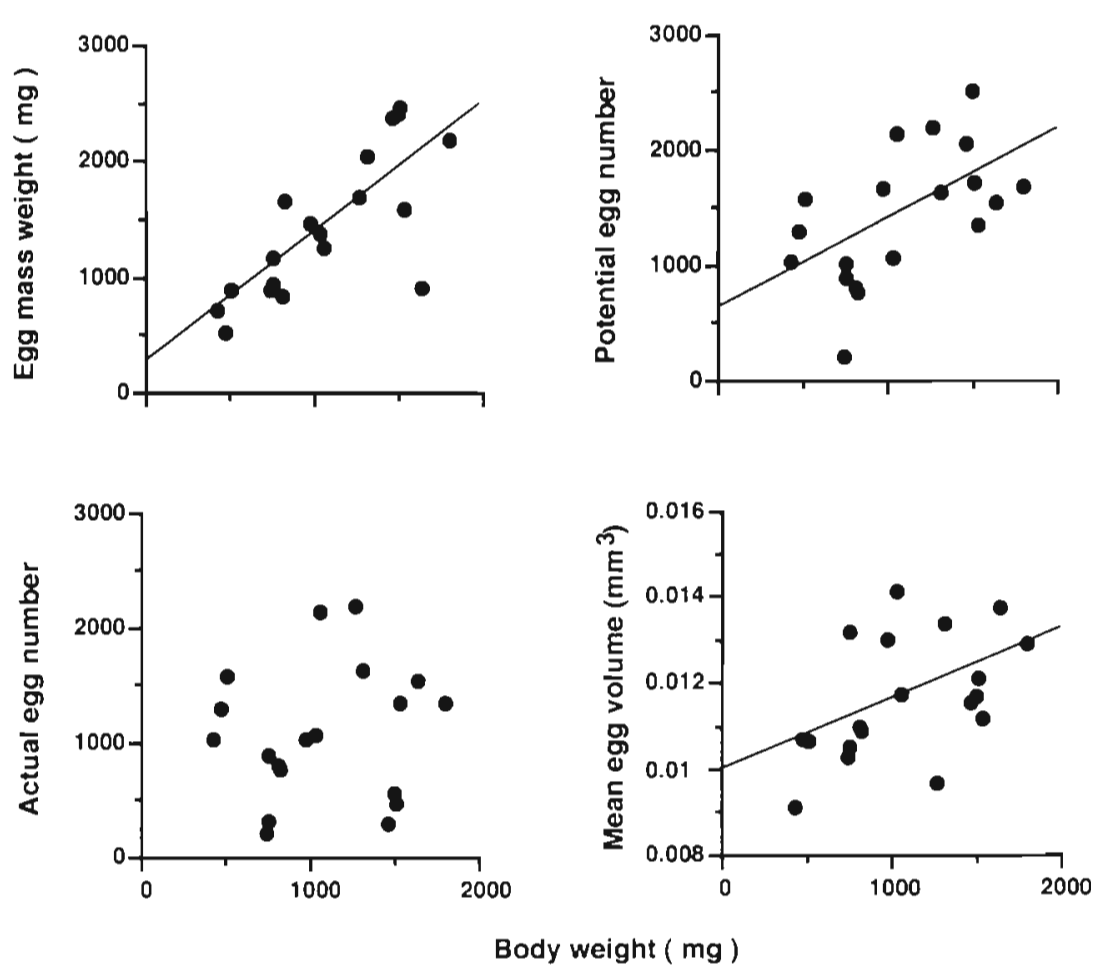

Fig. 4. Haloa japonica. Relationships between maternal size expressed as body weight at the start of the experiment and 4 characteristics of the first egg laying in 19 individuals. Regression equation: egg mass weight, $y=1.12 x+258\left(\mathrm{r}^{2}=\right.$ $0.581, p<0.0005)$, potential egg number, $y=0.775 x+612\left(\mathrm{r}^{2}=0.239, \mathrm{p}<0.05\right)$, mean egg volume, $y=0.00000164 x+0.00994\left(r^{2}=0.239, p<0.05\right)$. The relationship between maternal size and actual egg number is not significant $(p>0.05)$ 

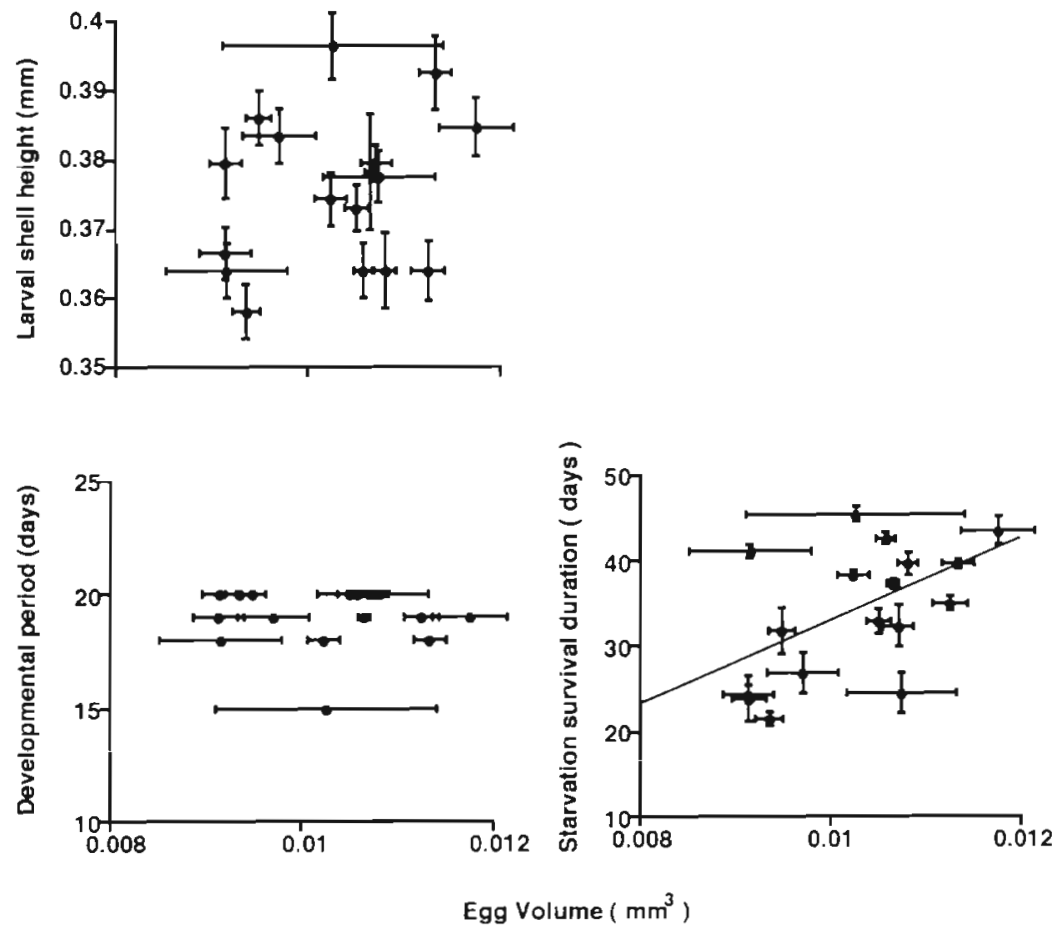

Fig. 5. Haloa japonica. Relationships between larval characteristics and mean egg volume of 17 egg masses from 5 individuals. Larval shell height and starvation survival duration are indicated by the mean value within each egg mass, and developmental period is indicated by the number of days from spawning to first hatching in each egg mass. The relationship between egg volume and length of survival under conditions of starvation is significant. Regression equation: $y=4940 x-16.7\left(r^{2}=0.284, p<0.05\right)$

\section{Egg-size and -number decline in Haloa japonica and implications of Begon \& Parker's model}

This study reveals that maternal age has a significant effect on not only egg size but also egg number within an egg mass. As with egg size, egg number also decreased with increasing maternal age (Tables $1 \& 2$ ). These patterns are also found in field cage experiments under ambient, food-limited conditions (author's unpubl.). Therefore, the tendency of egg size and egg number to decline with maternal age appears to be an intrinsic characteristic in this species in Kattoshi. Why do egg size and number of Haloa japonica decrease with maternal age? Such declines in fecundity with maternal age have been briefly described in some gastropods; Thompson (1958), for example, examined groups of the nudibranch Adalaria proxima and found that mean egg size appeared to decrease through the breeding season. Egg-number decline late in the breeding season has also been noted in some opisthobranchs (Macginitie 1934. Thompson 1958, but see also Gibson \& Chia 1995)
Studies of reproductive investment in other taxonomic groups, such as annual plants (Cavers \& Steel 1984, Thompson \& Pellmyr 1989, Stamp 1990, Kane \& Cavers 1992), insects (Wiklund \& Persson 1983, Ruohomäki et al. 1993, Braby \& Jones 1995), and a marine polychaete (Qian \& Chia 1992), also show the same pattern of declining egg size during the reproductive season. Interestingly, these organisms and opisthobranchs share a similar reproductive feature; they all have a single reproductive season per lifetime. Based on insect data, Begon \& Parker (1986) proposed a simple model to explain the ultimate factor responsible for the decline in offspring size and numbers in invertebrates. This model deals with females that do not feed as aduits and are subject to mortality during the production of successive clutches of offspring. The model suggests that the females should produce higher numbers of larger eggs in early clutches because of the reduced probability of surviving to lay a later clutch. They suggest that this model can be broadly applied to various organisms that feed little after beginning their reproductive phase.

Haloa japonica may meet the preconditions of Begon \& Parker's model. First, H. japonica at Kattoshi has only 1 reproductive season per lifetime and dies after the spawning season (Ito et al. 1996, present study). In addition, $H$. japonica cannot feed sufficiently on algae during the reproductive season at Kattoshi; food algal resources almost completely disappear during the reproductive season (Ito et al. 1996). Additionally, there are few fragments of algae in their feces in this season (author's pers. obs.) Moreover, a rapid decrease in wet weight was detected from field samples during the spawning season (Ito et al. 1996). In contrast, the adults of $H$. japonica that have sufficient food still grow during the early spawning season (author's unpubl. datal. These results imply that $H$. japonica feed little after beginning their reproductive phase under natural conditions. The food-limited environment may have favored the reproductive strategy of egg-size and -number decline in H. japonica.

There are 2 more assumptions of the Begon \& Parker model: (1) offspring fitness increases with increasing egg size and (2) offspring fitness decreases with increasing clutch size (Begon \& Parker 1986). Strictly 
speaking, I could not measure the larval fitness in the sense intended by Begon \& Parker because the mortality process of Haloa japonica larva under ambient conditions is still not clear. However, the first assumption seems to be true in this study; larval survival duration under starvation conditions was positively correlated with egg volume (Fig. 5). Hatched larvae of $H$. japonica may be able to use only limited algal resources; small $H$. japonica (shell height 1 to $2 \mathrm{~mm}$ ) were found on mainly filamentous, patchily distributed algae (e.g. Callithamnion sp. Dasya sp.) in autumn (author's pers. obs.). Juveniles of another generalist opisthobranch, Aplysia californica, are also found almost exclusively on a rare alga, Plocamium cartilagineum (<1\% cover) (Pennings 1990). Long survival duration may allow hatched larvae access to the limited algal food and increase their fitness.

Nevertheless, I have no definite information on the second assumption in Haloa japonica. However, this relationship may also apply. One reason is that embryos within larger egg masses (which contain more eggs) develop more slowly than those within smaller egg masses. In another cephalaspidean gastropod, Melanochlamys dimedea (Bergh), embryos within larger gelatinous egg masses develop more slowly than within divided smaller egg masses because the larger, thicker egg mass jelly slows gas exchange (Chaffee \& Strathmann 1984). Prolonged development of non-brooded benthic embryos increases stagespecific mortality and decreases their fitness.

Begon \& Parker's optimal model also makes an important prediction: there will be a tendency for the first eggs (and/or first clutches) spawned by larger females to be larger than those of smaller females (Begon \& Parker 1986). This prediction can easily be tested, and some authors have demonstrated a positive correlation between maternal body size and the size of the first egg mass spawned in lepidopteran species (Murphy et al. 1983, Begon \& Parker 1986). My data indicate the relationships between maternal body size and egg size, potential egg number, and weight of egg mass of Haloa japonica are as predicted by the model (Fig. 4). These results support my conclusion that Begon \& Parker's general theory can explain the decline of $H$. japonica egg size.

\section{Other explanations for egg-size decline}

Can other explanations for the egg-size decline apply? The algal food environment at Kattoshi changes as the season progresses (Ito et al. 1996), so the supply of nutrients available to developing eggs is not constant. The condition of food available to mature females can influence reproductive characteristics directly in various organisms (Bayne et al. 1978, Clark \& Goetzfried 1978, Kaplan 1987, Chester 1996). For example, nudibranches, such as Tenellia adspersa, produce smaller eggs with maternal starvation, and these smaller eggs tend to undergo pelagic lecithotrophic development (Clark \& Goetzfried 1978, Chester 1996). Chester (1996) suggested that the eggsize and larval type variation related to the adult's nutritional regime is a 'bet-hedging' strategy for an unstable environment. Thus, temporal and spatial variation of food resources may cause egg-size variation of Haloa japonica within a population under natural conditions. However, this effect cannot explain my results because all $H$. japonica in my experiment were amply supplied with food algae. Thus, egg-size variation in my study may have a genetic or ontogenetic component.

Qian \& Chia (1992) found that egg size, number, and energy content of a marine polychaete, Capitella sp., decreased with maternal age under laboratory conditions, and explained that the decrease of fecundity was due to the depletion of an adult's resources for reproduction. Many authors have explained this reproductive pattern based on the 'resource depletion hypothesis' (e. g. Wiklund \& Karlsson 1984). However, the theoretical base of this hypothesis is not explained by itself: as reproductive reserve declines the (optimal) egg size should also decline. In other words, this hypothesis can provide only a mechanism for the eggsize decline with maternal age, but it makes no suggestion as to why the mechanism should have been adapted (Begon \& Parker 1986, Roff 1992).

One would expect to find selective advantages to the parent animal in producing larger eggs first. If larval survival chance increases as the breeding season progresses (because of increased food availability, etc.), egg-size decline would be an adaptive strategy for parent Haloa japonica. However, I do not believe that this hypothesis can be used to explain my results. One reason is that this hypothesis is contradicted by the decline in clutch size; if there is a higher survival possibility of young later in the breeding season, a female should produce more eggs as the season progresses. In the last egg mass, however, $H$. japonica produced smaller and fewer eggs than in the first egg mass (Table 2).

In conclusion, egg size and number of Haloa japonica decrease in the course of the breeding season. This reproductive pattern is similar to that of other taxonomic groups, such as annual plants, insects and a marine polychaete. The decrease of reproductive investment is best explained as a maternal investment strategy related to maternal mortality proposed by Begon \& Parker (1986). My data supports the prediction of their theory. 
Acknowledgements. I thank Dis S. Nakao, S. Goshima, and T Noda for their kind advice, suggestions, and comments. I thank S. Wada, T. Sonoda and Y. Miyamoto and 4 anonymous reviewers for critical reading of the manuscript. $M$. Ito and the members of the Laboratory of Benthology, Department of Marine Biological Science, Faculty of Fisheries, Hokkaido University, provided a great deal of help with the field aspects of this study. I thank J. R. Bower for reading the English text.

\section{LITERATURE CITED}

Baur A (1994) Within- and between-clutch variation in egg size and nutrient content in the land snail Arianta arbustorum. Funct Ecol 8:581-586

Baur B (1990) Seasonal changes in clutch size, egg size and mode of oviposition in Ananta arbustoroum L. (Gastropoda) from Alpine populations. Zool Anz 225:253-264

Bayne BL, Holland DL, Moore MN, Lowe DM, Widdows J (1978) Further studies on the effects of stress in the adult on the egg of Mytilus edulis. J Mar Biol Ass UK 58:825-841

Begon M, Parker GA (1986) Should egg size and clutch size decrease with age? Oikos 47:293-302

Braby MF (1994) The significance of egg size variation in butterflies in relation to hostplant quality. Oikos 71:119-129

Braby MF, Jones RE (1995) Reproductive patterns and resource allocation in tropical butterflies: influence of adult diet and seasonal phenotype on fecundity, longevity and egg size. Oikos 72:189-204

Bretagnolle F, Thompson JD, Lumaret $R$ (1995) The influence of seed size variation on seed germination and seedling vigour in diploid and tetraploid Dactylis glomerata L. Ann Bot 76:607-615

Cavers PB, Steel MG (1984) Patterns of change in seed weight over time in individual plants. Am Nat 124:324-335

Chaffee C. Strathmann RR (1984) Constraint on egg masses. I. Retarded development within thick egg masses. I Exp Mar Biol Ecol 84:73-83

Chester CM (1996) The effect of adult nutrition on the reproduction and development of the estuarine nudibranch, Tenellia adspersa (Nordmann, 1845). J Exp Mar Biol Ecol 198:113-130

Clark KB, Goetzfried A (1978) Zoogeographic influences on development patterns of north atlantic ascoglossa and nudibranchia, with a discussion of factors affecting egg size and number. J Mollusc Stud 44:283-294

Estebenet AL, Cazzaniga NJ (1993) Egg variability and the reproductive strategy of Pomacea canaliculata (Gastropoda: Ampullariidae). Apex 8:129-138

Eyster LS (1979) Reproduction and developmental varability in the opisthobranch Tenellia pallida. Mar Biol 51: $133-140$

Gibson GD, Chia FS (1995) Developmental variability in the poecilogonous opisthobranch Haminaea callidegenita: life-history traits and effects of environmental parameters. Mar Ecol Prog Ser 121:139-155

Glazier DS (1992) Effect of food, genotype, and maternal size and age on offspring investment in Daphnia magna. Ecology 73:910-926

Hamatani I (1986) Cephalaspidea. In: Okutani T (ed) Ketteiban Seibutsu Dai Zukan, Kairui. (Compendium of Mollusca in Japan). Sekai Bunka Sha, Tokyo, p 209-212 (in Japanese)

Hirano YJ, Hirano YM (1991) Poecilogony or cryptic species? Two geographically different development patterns observed in 'Cuthona pupillae (BABA, 1961)' (Nudibranchia: Aeolidoidea). J Mollusc Stud 57:133-141
Hurst A (1967) The egg masses and veligers of thirty Northeast Pacific opisthobranchs. Veliger 9:255-288

Ito K, Nakao S, Goshima S (1996) Growth and reproduction of the generalist opisthobranch, Haloa japonica: effect of algal seasonality on growth rate. Mar Biol 126: $395-401$

Kane M. Cavers PB (1992) Patterns of seed weight distribution and germination with time in a weedy biotype of proso millet (Panicum miliaceum). Can J Bot 70:$562-567$

Kaplan RH (1987) Developmental plasticity and maternal effects of reproductive characteristics in the frog, Bombina orientalis, Oecologia 71:273-279

Lalonde RG (1991) Optimal offspring provisioning when resources are not predictable. Am Nat 138:680-686

Macginitie GE (1934) The egg-laying activites of the sea hare, Tethys californicus (Cooper). Biol Bull 67:300-303

McEdward LR, Carson SF (1987) Variation in egg organic content and its relationship with egg size in the starfish Solaster stimpsoni. Mar Ecol Prog Ser 37:159-169

McEdward LR, Chia FS (1991) Size and energy content of eggs from echinoderms with pelagic lecithotrophic development. J Exp Mar Biol Ecol 147:95-102

McGinley MA (1989) The influence of a positive correlation between clutch size and offpring fitness on the optimal offspring size. Evol Ecol 3:150-156

Murphy DD, Launer AE, Ehrlich PR (1983) The role of adult feeding in egg production and population dynamics of the checkerspot butterfly Euphydryas editha. Oecologia 56: 257-263

Parker GA, Begon M (1986) Optımal egg size and clutch size: effects of environment and maternal phenotype. Am Nat 128:573-592

Pennings SC (1990) Size-related shifts in herbivory: speciallzation in the sea hare Aplysia californica Cooper J Exp Mar Biol Ecol 1.42:43-61

Qian PY, Chia FS (1992) Effect of aging on reproduction in marine polychaete Capitella sp. J Exp Mar Biol Ecol 156. $23-38$

Roff DA (1992) The evolution of life histories; theory and analysis. Chapman \& Hall, New York

Ruohomäki K, Hanhimäki S, Haukioja E (1993) Effects of egg size. laying order and larval density on performance of Epirita autumnata (Lep. Geometridae). Oikos 68 $61-66$

Smith CC, Fretwell SD (1974) The optimal balance between size and number of offspring. Am Nat 108:499-506

Stamp NE (1990) Production and effect of seed size in a grassland annual (Erodium brachycarpum, Geraniaceae). Am J Bot 77:874-882

Tessier AJ, Consolattr NL (1989) Variation in offspring size in Daphnia and consequences for individual fitness. Oikos 56:269-276

Tessier AJ, Henry LL, Goulden CE, Durand MW (1983) Starvation in Daphnia: Energy reserves and reproductive allocation. Limnol Oceanogr 28:667-676

Thompson JN, Pellmyr O (1989) Origins of varuance in seed number and mass: interaction of sex expression and herbivory in Lomatium salmoniflorum. Oecologia 79: 395-402

Thompson TE (1958) The influence of temperature on spawning in Adalaria proxima (A. \& H.) (Gastropoda Nudibranchiaj. Oikos 9:246-252

Thompson TE (1967) Direct development in a nudibranch Cadluna laevis, with a discussion of developmental processes in opisthobranchia. J Mar Biol Assoc UK 47: $1-22$ 
Tomiyama K, Miyashita K (1992) Variation of egg clutches in the giant African snail, Achatina fulica (Ferussac) (Stylommatophora: Achatinidae) in Ogasawara Islands. Venus Jpn J Malacol 51:293-301

Usuki I (1966a) The life cycle of Haloa japonica (Pilsbry) I.The larval development. Sci Rep Niigata Univ Ser D (Biol) 3: $87-105$

Usuki I (1966b) The life cycle of Haloa japonica (Pilsbry) II. Spawning and growth. Sci Rep Niigata Univ Ser D (Biol) 3: $107-121$

This artıcle was submitted to the editor
Wiklund C. Karlsson B (1984) Egg size variation in stayrid butterflies: adaptive vs historical, 'Bauplan', and mechanistic explanations. Oikos 43:391-400

Wiklund C, Persson A (1983) Fecundity, and the relation of egg weight variation to offspring fitness in the speckled wood butterfly Pararge aegeria, or why don't buttertly females lay more eggs? Oikos 40:53-63

Yusa Y (1994) Size-related egg production in a simultaneous hermaphrodite, the sea hare Aplysia kurodai Baba (Mollusca: Opisthobranchia). Publ Seto Mar Biol Lab 36:249-254

Manuscript first received: November 4, 1996

Revised version accepted: March 17, 1997 